\title{
CircFATI is Overexpressed in Colorectal Cancer and Suppresses Cancer Cell Proliferation, Invasion and Migration by Increasing the Maturation of miR-I0a
}

Meng Liu

Department of Oncology, China-Japan Friendship Hospital, Beijing, I00029, People's Republic of China
Correspondence: Meng Liu Department of Oncology, China-Japan Friendship Hospital, No. 2 East Yinghua Street, Chaoyang District, Beijing, 100029, People's Republic of China Email zhiqiangchengoncol@I63.com
Purpose: It has been reported that circFAT1 plays opposite roles in gastric cancer and osteosarcoma. This study aimed to explore the involvement of circFAT1 in colorectal cancer (CRC).

Patients and Methods: Paired CRC and non-tumor tissues from 64 CRC patients were subjected to RNA preparations and RT-qPCRs to determine the expression of circFAT1, premature miR-10a, and mature miR-10a. In CRC cells, the effects of circFAT1 overexpression on miR-10a maturation were analyzed by determining the expression of both premature miR-10a and mature miR-10a using RT-qPCRs. The role of circFAT1 and miR-10a in regulating the proliferation, invasion, and migration of CRC cells was analyzed by BrdU and Transwell assays, respectively.

Results: We found that circFAT1 was upregulated in CRC. Mature miR-10a, but not premature miR-10a, was overexpressed in CRC and positively correlated with circFAT1. CircFAT1 overexpression increased the expression of mature miR-10a, but not premature miR-10a. Overexpression of circFAT1 and miR-10a increased cell proliferation, invasion and migration, and miR-10a inhibitor suppressed cell behaviors and reversed the effects of circFAT1 overexpression.

Conclusion: circFAT1 is overexpressed in CRC and may suppress CRC cell proliferation, invasion and migration by increasing miR-10a maturation.

Keywords: colorectal cancer, circFAT1, miR-10a, maturation, invasion, migration

\section{Introduction}

Colorectal cancer (CRC) is among the most common types of cancers for both mortality and incidence in many countries, such as the United States and China. ${ }^{1,2}$ It is estimated that CRC affects about 1 out of 21 males and 1 out of 23 females during their lifetime. ${ }^{3}$ CRC patients only with localized tumors in the bowel are usually treatable with surgical resections in combination with chemotherapy and radiotherapy before and after treatment. ${ }^{4}$ However, a considerable portion of CRC patients are diagnosed with tumor metastasizing to distant sites, which is not curable in most cases. ${ }^{5,6}$ Therefore, novel therapeutic approaches are needed.

Molecular target therapies are novel anti-cancer approaches that can be performed to suppress cancers by regulating related gene expression. ${ }^{7-9}$ The increased elucidation of the molecular mechanism of CRC has shown that some molecular 
players, such as IL-6, BRAF, PIK3CA, KRAS, and PTEN, have been characterized as potential targets for targeted anti-CRC therapy. ${ }^{8,9}$ However, more effective and safe targets are needed to further improve the efficiency and safety of targeted therapy before clinical applications. ${ }^{10}$ Even without protein-coding ability, circular RNAs (circRNAs) regulate gene expression to participate in cancer biology. ${ }^{11,12}$ Therefore, circRNAs may be targeted to treat cancers. ${ }^{13}$ However, the functionality of most circRNAs in cancer biology remains to be further characterized. Previous studies have shown that circRNA circFAT1 plays opposite roles in gastric cancer and osteosarcoma. ${ }^{14,15}$ This study aimed to explore the role of circFAT1 in CRC.

\section{Patients and Methods}

\section{Tissue Acquisition from CRC Patients}

A total of 64 CRC patients (38 males and 26 females; $57.3 \pm 6.9$ years) diagnosed as CRC through histopathological tests at China-Japan Friendship Hospital were enrolled. This hospital Ethics Committee approved this study. This study excluded patients diagnosed with multiple clinical disorders, initiated therapy, or history of any types of malignancies and recurrent CRC to eliminate other factors that may affect gene expression and only included newly diagnosed cases. The $64 \mathrm{CRC}$ patients were divided into AJCC stage I or II $(\mathrm{n}=29)$ and III or IV $(n=35)$. Paired CRC and adjacent (within an area of $3 \mathrm{~cm}$ around tumors) non-tumor tissue samples were collected from each patient. All tissue samples were proven correct by histopathological exams and kept in liquid nitrogen prior to the subsequent assays. All patients signed informed consent.

\section{CRC Cells and Transient Transfections}

Three human CRC cell lines, HT-29, WiDr, and SW480 from ATCC (USA), were used in this study. They were cultured in McCoy's 5a medium supplemented with FBS $(10 \%)$ at $37^{\circ} \mathrm{C}$ in an incubator with $95 \%$ humidity and $5 \%$ $\mathrm{CO}_{2}$ and subjected to subsequent assays at about $80 \%$ confluency.

WiDr and HT-29 cells were transfected with circFAT1 expression vector or mimic of miR-10a to overexpress both circFAT1 and miR-10a. These cells were also transfected with miR-10a inhibitor to silence miR-10a. CircFAT1 expression vector was established with backbone vector pcDNA3.1 (Invitrogen). Mimic of miR-10a and negative control (NC) miRNA as well as miR-10a inhibitor and $\mathrm{NC}$ inhibitor were designed and prepared by Sangon Biotech (Shanghai, China). All transfections were performed using lipofectamine 2000 (Invitrogen). Untransfected cells were control (C) cells in all transfections. $\mathrm{NC}$ experiments were performed by transfecting the cells with empty vector, NC inhibitor, or NC miRNA. The transfected cells were cultured in a fresh medium for $48 \mathrm{~h}$ prior to the subsequent assays.

\section{RNA Preparations}

WiDr and HT-29 cells and the tissues from all 64 CRC patients were used to isolate total RNA using Ribozol (Invitrogen). All RNA samples were digested with DNase I (Invitrogen) until the OD 260/280 ratio reached about 2.0, indicating pure RNA samples. RNA integrity was analyzed using urea-PAGE gels.

\section{RT-qPCRs}

The preparation of cDNA samples was performed through reverse transcriptions (RTs) using RNA samples of high quality. All RTs were performed using RT-PCR Quick Master Mix (Toyobo). To analyze circFAT1 expression, qPCRs were performed using SYBR Green Master Mix (Bio-Rad) with 18S rRNA as the internal control.

The expression of both premature and mature miR-10a was determined using an All-in-One ${ }^{\mathrm{TM}}$ miRNA qRT-PCR reagent kit (GeneCopoeia). Sequence-specific primers were used to perform RTs and qPCRs to analyze premature miR-10a expression. Prior to the analysis of mature miR-10a expression, poly (A) was added, followed by using poly $(\mathrm{T})$ to perform RTs and qPCRs. The $2^{-\Delta \Delta C t}$ method was used to normalize $\mathrm{Ct}$ values to endogenous controls.

\section{BrdU Assay}

Cells with transfections were cultured in a 96-well cell culture plate $(0.1 \mathrm{~mL}$ cell suspension containing 3000 cells per well) for $48 \mathrm{~h}$. After that, $10 \mathrm{mM}$ BrdU was added, and cells were incubated for $2 \mathrm{~h}$. After cell fixation for $2 \mathrm{~h}$, peroxidase-coupled anti-BrdU-antibody (Sigma-Aldrich) was applied, and cells were further incubated for $48 \mathrm{~h}$. After that, cells were washed and incubated with peroxidase substrate for $2 \mathrm{~h}$. Finally, OD values at $450 \mathrm{~nm}$ were determined to analyze cell proliferation. 


\section{Transwell Assays}

Corning Transwell Inserts $(8.0 \mu \mathrm{m})$ were used to analyze the invasion and migration of CRC cells with transfections. Briefly, cells transfected with circFAT1 or mature miR-10a for $24 \mathrm{~h}$ were used to prepare serum-free cell suspensions. The upper chamber was filled with cell suspension (5000 cells per well), and the lower chamber was filled with medium $(20 \% \mathrm{FBS})$. It is worth noting that Matrigel (Corning) was used to coat membranes for $12 \mathrm{~h}$ at $37^{\circ} \mathrm{C}$ prior to invasion assays. Cells were cultured for $24 \mathrm{~h}$, and the upper surface of the membranes was cleaned with a cotton swab. After that, the lower surface of the membranes was stained with $1 \%$ crystal violet (SigmaAldrich) for 30 minutes in the dark. Finally, a light microscope was used to count cells.

\section{Statistical Analysis}

Heatmaps plotted using Heml 1.0 were used to express differential gene expression in paired tissues. ANOVA
Tukey's test was used to compare multiple independent groups. Correlations were analyzed using Spearman correlation coefficient. $\quad \mathrm{P}<0.05$ was statistically significant.

\section{Results}

\section{CRC Tissues Exhibited Altered Expression of circFATI and Mature miR-10a}

Tissue samples from a total of 64 CRC patients were subjected to total RNA extractions and RT-qPCRs to analyze the expression of circFAT1, mature miR-10a, and premature miR-10a in CRC. Heatmap analysis showed that circFAT1 was upregulated in CRC (Figure 1A). Mature miR-10a (Figure 1B), but not premature miR-10a (Figure 1C), was overexpressed in CRC. Therefore, circFAT1 overexpression and miR-10a maturation may participate in CRC.

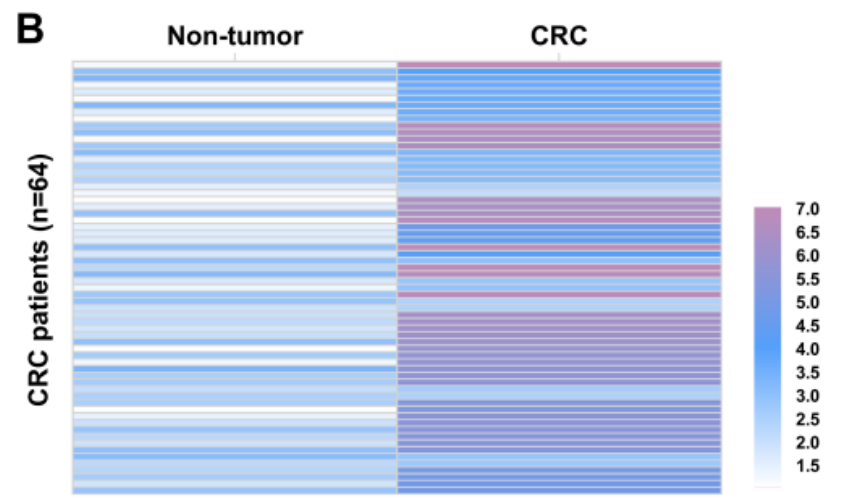

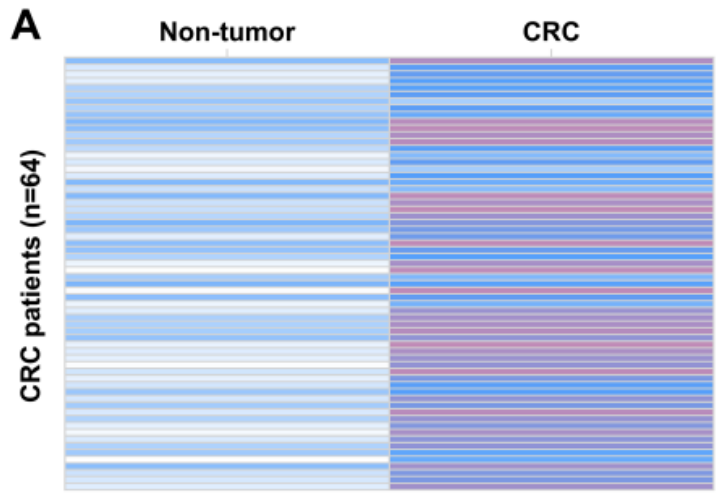
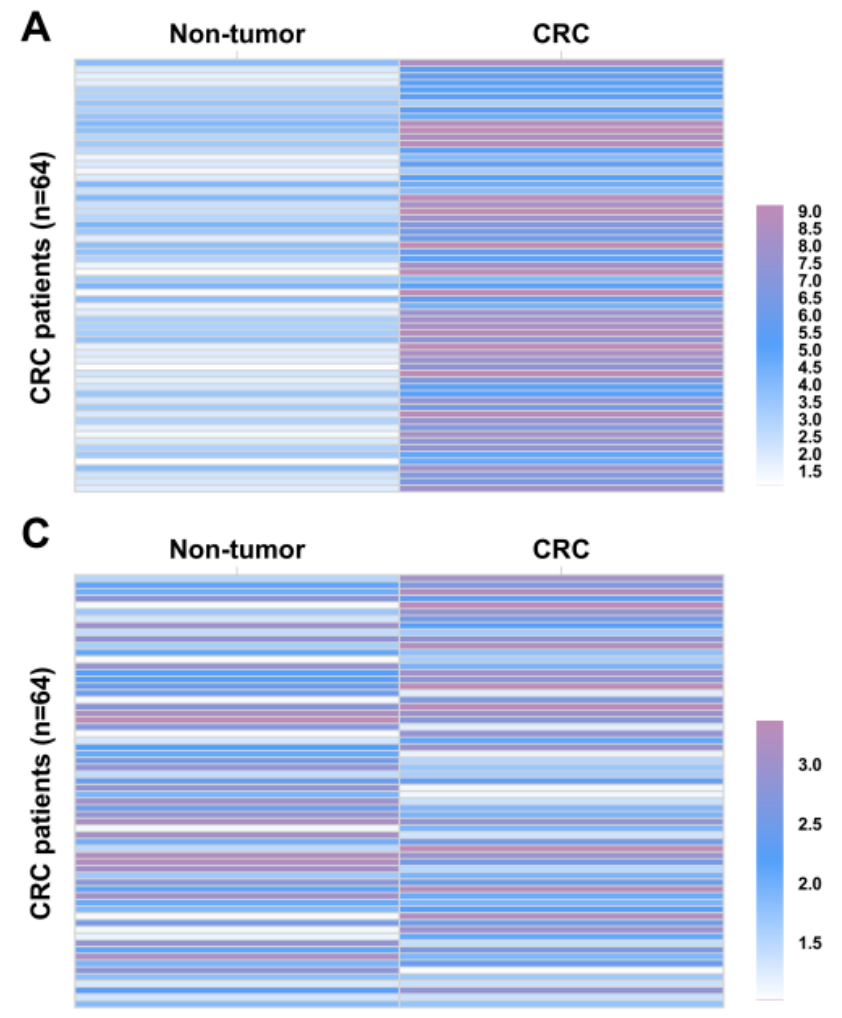

Figure I CRC tissues exhibited altered expression of circFATI and mature miR-10a. Tissue samples from a total of 64 CRC patients were subjected to total RNA extractions and RT-qPCRs to analyze the expression of circFATI (A), mature miR-I0a (B) and premature miR-I0a (C) in CRC. Heatmaps plotted using Heml I.0 were used to express differential gene expression in paired tissues. 
A

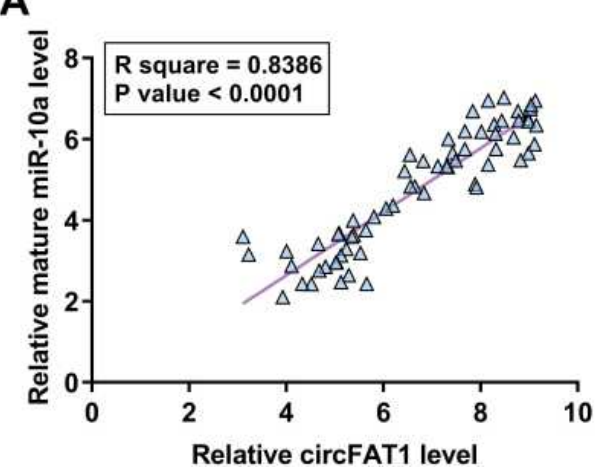

B

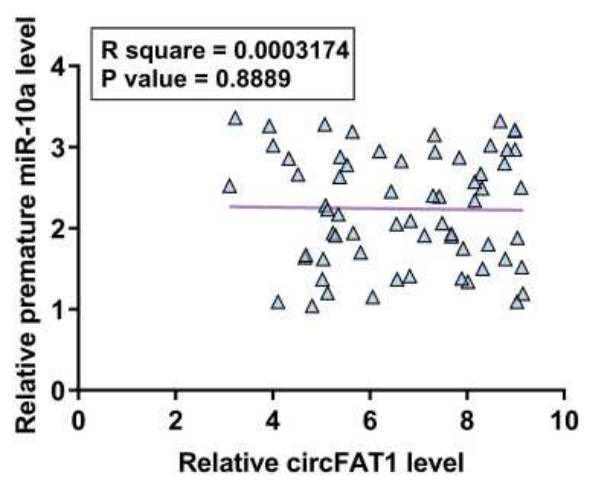

Figure 2 MiR-10a was positively and significantly correlated with circFATI. The correlations between circFATI and mature miR-10a (A) or premature miR-10a (B) across both CRC tissues were analyzed by Pearson's correlation coefficient.

\section{MiR-IOa Was Positively and Significantly Correlated with circFATI}

The correlations between circFAT1 and mature miR-10a or premature miR-10a across CRC tissues were analyzed by Pearson's correlation coefficient. A significant and positive correlation between circFAT1 and mature miR-10a was observed across CRC tissues (Figure 2A). In contrast, the correlation between circFAT1 and miR-10a across CRC tissues was not significant (Figure 2B).
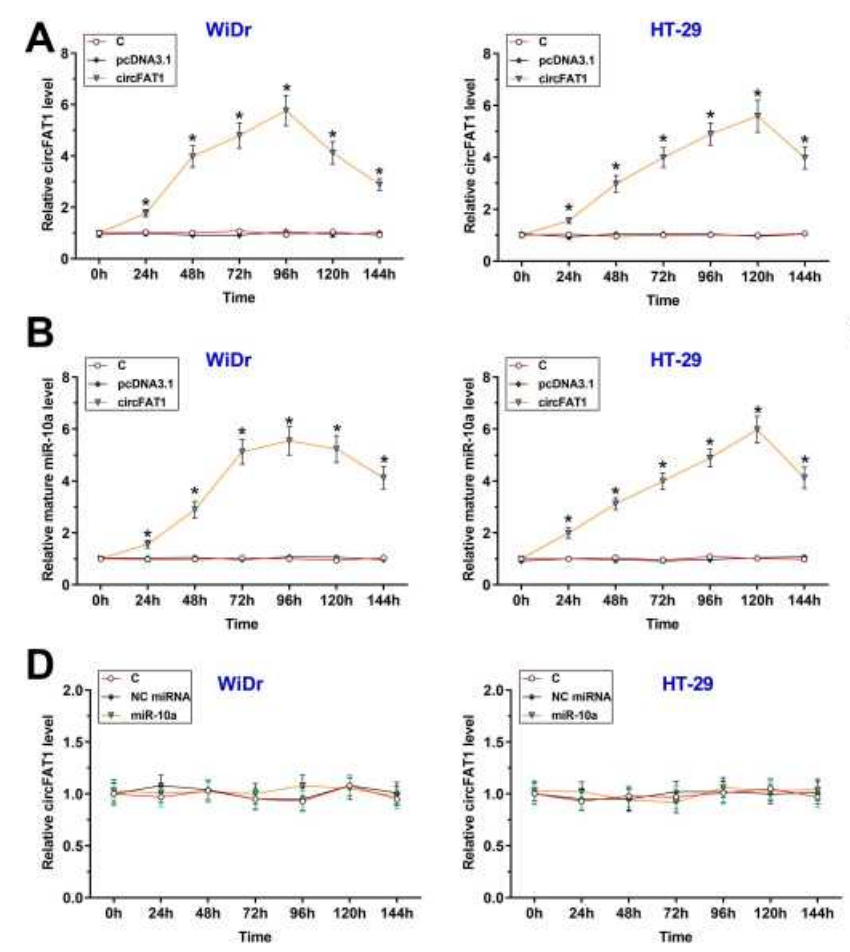

\section{CircFATI Overexpression Decreased miR-IOa Maturation in Both WiDr and HT-29 Cells}

The close correlation between circFAT1 and mature miR-10a across CRC tissues indicated the possible role of circFAT1 in regulating miR-10a maturation in CRC. To explore this possibility, WiDr and HT-29 cells were transfected with either circFAT1 expression vector or miR-10a mimic, followed by the confirmation of
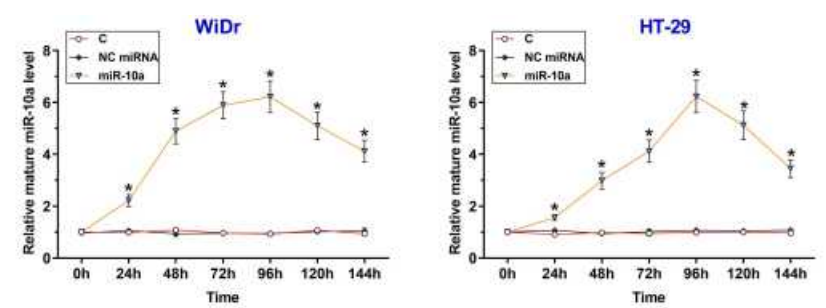

C
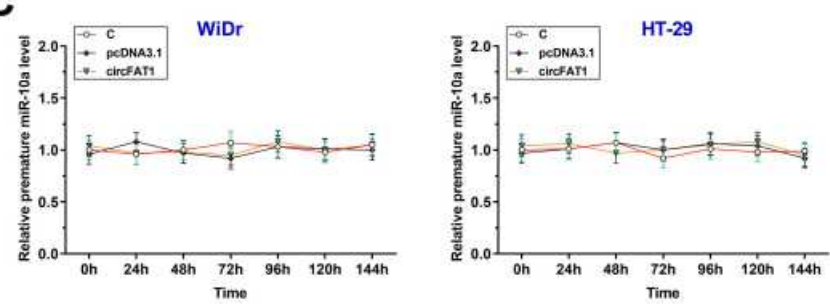

Figure 3 CircFATI overexpression decreased miR-I0a maturation in both WiDr and HT-29 cells. The close correlation between circFATI and mature miR-I0a across CRC tissues indicated the possible role of circFATI in regulating miR-I0a maturation in CRC. To explore this possibility, WiDr and HT-29 cells were transfected with either circFATI expression vector or miR-10a mimic, followed by the confirmation of the overexpression of circFATI and mature miR-I0a every $24 \mathrm{~h}$ until I44h (A). The effects of circFATI overexpression on the expression of mature miR-I0a (B) and premature miR-I0a (C), and the effects of mature miR-I0a overexpression on circFATI expression (D) were also analyzed by RT-qPCR. *p<0.05. 
circFAT1 and mature miR-10a overexpression every $24 \mathrm{~h}$ until $144 \mathrm{~h}$. It was observed that circFAT1 and mature miR-10a were significantly overexpressed in both cell lines from $24 \mathrm{~h}$ to $144 \mathrm{~h}$ (Figure $3 \mathrm{~A}, \mathrm{p}<0.05$ ). We also found that mature miR-10a was significantly overexpressed in SW480 cells (Supplementary Figure S1A). In addition, circFAT1 overexpression increased mature miR-10a expression (Figure 3B, $\mathrm{p}<0.05$ ), but failed to significantly affect premature miR-10a expression (Figure 3C). In addition, mature miR-10a overexpression also failed to significantly affect circFAT1 expression (Figure 3D). Therefore, circFAT1 may increase miR-10a maturation in CRC cells.

\section{CircFATI Overexpression Increased CRC Cell Proliferation, Invasion and Migration via miR-IOa}

The roles of circFAT1 and miR-10a in regulating the proliferation, invasion and migration of $\mathrm{CRC}$ cells were analyzed using the BrdU assay (Figure 4A) and Transwell invasion (Figure 4B) and migration (Figure 4C) assays, respectively. Our data showed that overexpression of circFAT1 and miR-10a increased cell proliferation, invasion, and migration, and miR-10a inhibitor suppressed cell behaviors and reversed the effects of circFAT1 overexpression $(\mathrm{p}<0.05)$. Moreover, miR-10a overexpression facilitated SW480 cell proliferation, invasion, and migration, while

A
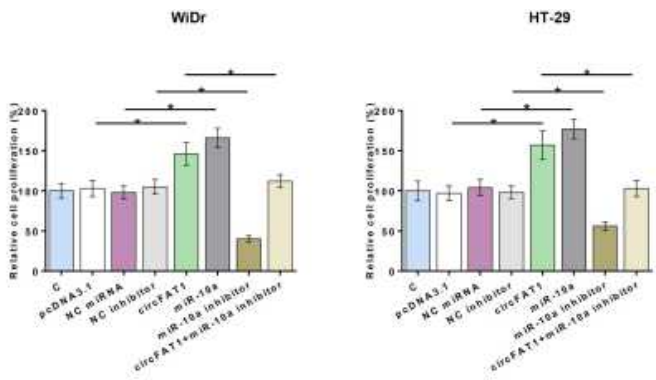

B
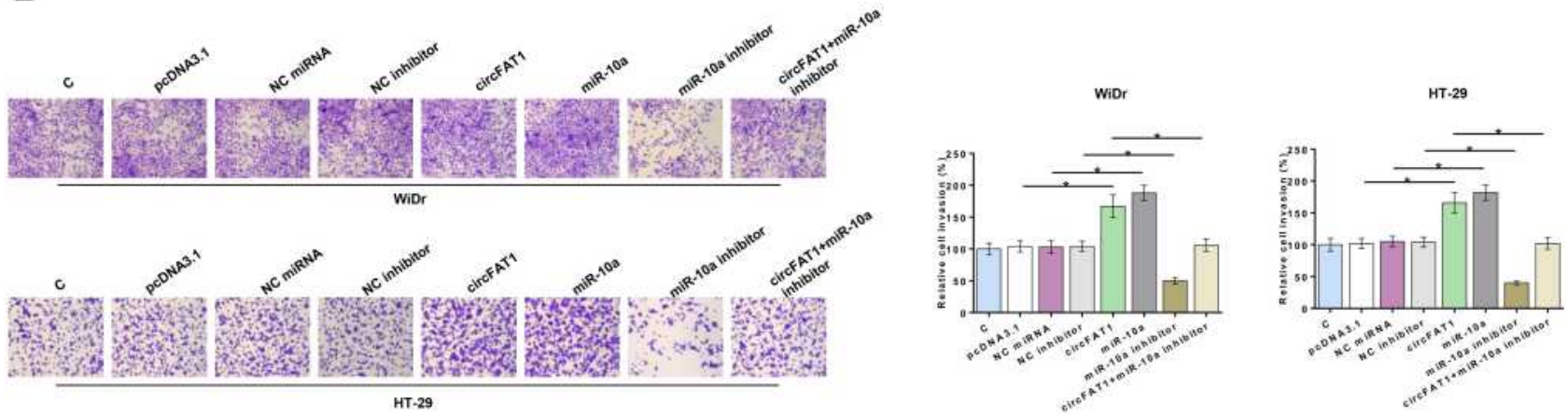

C
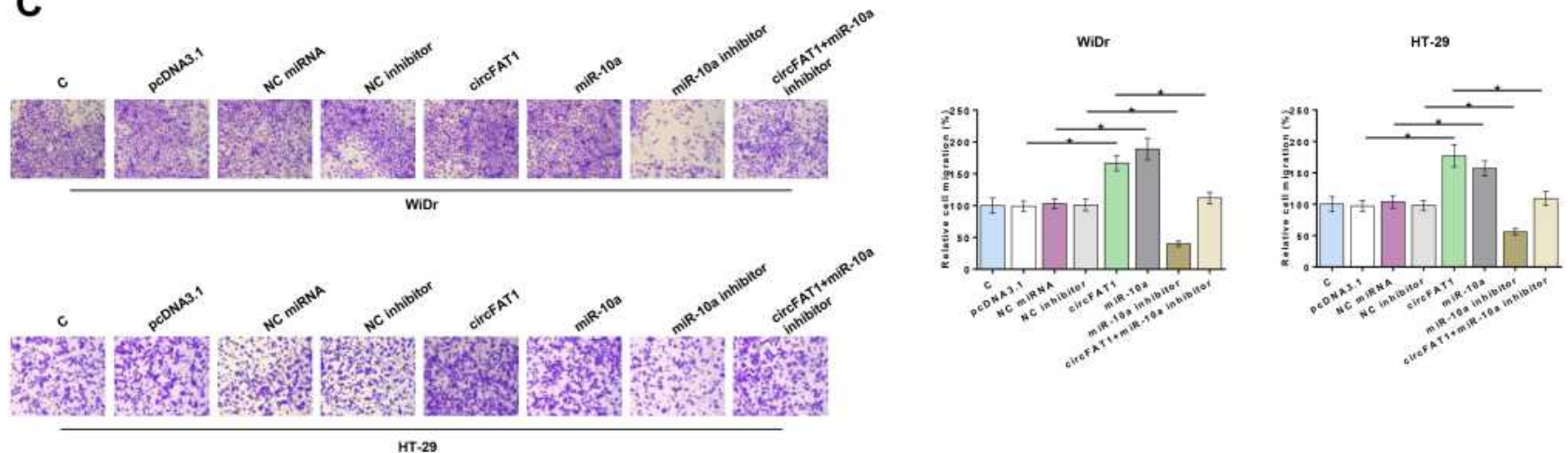

Figure 4 CircFATI overexpression of increased CRC cell proliferation, invasion, and migration through miR-I0a. The role of circFATI and miR-I0a in regulating CRC cell proliferation, invasion, and migration were analyzed by BrdU assay $(\mathbf{A})$ and Transwell invasion $(\mathbf{B})$ and migration $(\mathbf{C})$ assays, respectively. ${ }^{*}<0.05$. 
miR-10a inhibition attenuated SW480 cell proliferation, invasion, and migration (Supplementary Figure S2A-C).

\section{Discussion}

The involvement of circFAT1 in CRC and the crosstalk between circFAT1 and miR-10a were explored in this study. We found that circFAT1 was overexpressed in $\mathrm{CRC}$ and it may increase the maturation of miR-10a, a critical player in cancer biology, ${ }^{16}$ to increase CRC cell proliferation, invasion and migration.

Interestingly, two previous studies have reported the opposite roles of circFAT1 in gastric cancer and osteosarcoma. ${ }^{14,15}$ In osteosarcoma, circFAT1 is significantly overexpressed, and its overexpression increases HK2 expression by serving as an endogenous competing RNA of miR-181b, which in turn promotes cancer cell proliferation and migration. ${ }^{15}$ In contrast, significantly under-expressed circFAT1 is observed in gastric cancer, and circFAT1 overexpression suppresses cancer cell proliferation, invasion, and migration of gastric cancer cells by sponging miR-548a to upregulate $\mathrm{YBX} 1{ }^{14}$ In this study, we reported circFAT1 upregulation in CRC and its enhancing effects on cancer cell proliferation, invasion, and migration. Therefore, circFAT1 plays oncogenic roles in CRC.

MiR-10a also plays different roles in different types of cancers. ${ }^{16,17}$ MiR-10a is overexpressed in cervical cancer and targets CHL1 to increase cancer cell invasion, proliferation, and migration. ${ }^{17}$ However, a previous study showed that miR10a suppresses CRC metastasis to play tumor suppressive roles. ${ }^{16}$ In contrast, our study reported the overexpression of mature miR-10a, but not premature miR-10a, in CRC and the enhancing effects of miR-10a on cell proliferation, invasion, and migration. This is possible due to the different patients and cell lines included in this study. However, future studies are needed to further analyze the expression pattern and function of miR-10a in CRC.

It is known that circFAT1 participates in cancer biology mainly by sponging miRNAs. ${ }^{14,15}$ Interestingly, we showed that circFAT1 increases miR-10a maturation to promote CRC. Considering that miR-10a maturation requires the transportation of premature miRNA from the nucleus to the cytoplasm, circFAT1 may increase miR-10a maturation by promoting premature miR-10a movement.

In conclusion, circFAT1 is overexpressed in CRC. CircFAT1 increases cancer cell proliferation, invasion, and migration mainly by increasing miR-10a maturation.

\section{Data Sharing Statement}

The datasets analyzed during the current study are available from the corresponding authors on reasonable request.

\section{Ethics Approval and Informed Consent}

This study was approved by the Ethics Committee of China-Japan Friendship Hospital. This study was conducted in accordance with the Declaration of Helsinki.

\section{Acknowledgments}

The authors would like to express our gratitude for those who have critically reviewed this manuscript and those who gave us help during the experiment.

\section{Funding}

This work was supported by no funders.

\section{Disclosure}

The author reports no conflicts of interest in this work.

\section{References}

1. Siegel R, Desantis C, Jemal A. Colorectal cancer statistics, 2014. CA Cancer J Clin. 2014;64(2):104-117. doi:10.3322/caac.21220

2. Liu S, Zheng R, Zhang M, Zhang S, Sun X, Chen W. Incidence and mortality of colorectal cancer in China, 2011. Chin J Cancer Res. 2015;27 (1):22-28.

3. Siegel RL, Miller KD, Fedewa SA, et al. Colorectal cancer statistics, 2017. CA Cancer J Clin. 2017;67(3):177-193. doi:10.3322/caac.21395

4. El-Shami K, Oeffinger KC, Erb NL, et al. American cancer society colorectal cancer survivorship care guidelines. CA Cancer J Clin. 2015;65(6):428-455. doi:10.3322/caac.21286

5. Edwards MS, Chadda SD, Zhao Z, Barber BL, Sykes DP. A systematic review of treatment guidelines for metastatic colorectal cancer. Colorectal Dis. 2012;14(2):e31-47. doi:10.1111/j.1463-1318.2011.02765.x

6. Van Cutsem E, Cervantes A, Nordlinger B, Arnold D. Metastatic colorectal cancer: ESMO clinical practice guidelines for diagnosis, treatment and follow-up. Ann Oncol. 2014;25 Suppl 3:1-9.

7. Heinemann V, Douillard JY, Ducreux M, Peeters M. Targeted therapy in metastatic colorectal cancer - an example of personalised medicine in action. Cancer Treat Rev. 2013;39(6):592-601. doi:10.1016/j. ctrv.2012.12.011

8. Guo Y, Xu F, Lu T, Duan Z, Zhang Z. Interleukin-6 signaling pathway in targeted therapy for cancer. Cancer Treat Rev. 2012;38 (7):904-910. doi:10.1016/j.ctrv.2012.04.007

9. De Roock W, De Vriendt V, Normanno N, Ciardiello F, Tejpar S. KRAS, BRAF, PIK3CA, and PTEN mutations: implications for targeted therapies in metastatic colorectal cancer. Lancet Oncol. 2011;12(6):594-603. doi:10.1016/S1470-2045(10)70209-6

10. Sanna V, Pala N, Sechi M. Targeted therapy using nanotechnology: focus on cancer. Int J Nanomed. 2014;9:467-483.

11. Shang Q, Yang Z, Jia R, Ge S. The novel roles of circRNAs in human cancer. Mol Cancer. 2019;18(1):6. doi:10.1186/s12943-018-0934-6

12. Zhou R, Wu Y, Wang W, et al. Circular RNAs (circRNAs) in cancer. Cancer Lett. 2018;425:134-142. doi:10.1016/j.canlet.2018.03.035 
13. Lei B, Tian Z, Fan W, Ni B. Circular RNA: a novel biomarker and therapeutic target for human cancers. Int J Med Sci. 2019;16 (2):292-301. doi:10.7150/ijms.28047

14. Fang J, Hong H, Xue X, et al. A novel circular RNA, circFAT1(e2), inhibits gastric cancer progression by targeting miR-548g in the cytoplasm and interacting with YBX1 in the nucleus. Cancer Lett. 2019;442:222-232. doi:10.1016/j.canlet.2018.10.040

15. Gu H, Cheng X, Xu J, et al. Circular RNA circFAT1(e2) promotes osteosarcoma progression and metastasis by sponging miR-181b and regulating HK2 expression. Biomed Res Int. 2020;2020:3589871. doi: $10.1155 / 2020 / 3589871$
16. Liu Y, Zhang Y, Wu H, et al. miR-10a suppresses colorectal cancer metastasis by modulating the epithelial-to-mesenchymal transition and anoikis. Cell Death Dis. 2017;8(4):e2739. doi:10.1038/ cddis. 2017.61

17. Long MJ, Wu FX, Li P, Liu M, Li X, Tang H. MicroRNA-10a targets CHL1 and promotes cell growth, migration and invasion in human cervical cancer cells. Cancer Lett. 2012;324(2):186-196. doi:10.1016/j.canlet.2012.05.022

\section{Publish your work in this journal}

Cancer Management and Research is an international, peer-reviewed open access journal focusing on cancer research and the optimal use of preventative and integrated treatment interventions to achieve improved outcomes, enhanced survival and quality of life for the cancer patient.
The manuscript management system is completely online and includes a very quick and fair peer-review system, which is all easy to use. Visit http://www.dovepress.com/testimonials.php to read real quotes from published authors. 